\title{
PENDAFTARAN HAK ATAS TANAH MELALUI PROGRAM NASIONAL AGRARIA (PRONA) TAHUN 2015 DI KABUPATEN AGAM (STUDI ATAS PELAKSANAAN PP NOMOR 24 TAHUN 1997 TENTANG PENDAFTARAN TANAH
}

\section{ANGGUN LESTARI SURYAMIZON, WENDY AFANDI}

Universitas Muhammadiyah Sumatera Barat

\begin{abstract}
Initially, Prona was implemented based on the Decree of the Minister of Home Affairs No. 189 of 1981 concerning the National Agrarian Operations Project. The project is tasked with processing land certificates en masse as an embodiment of the Catur Orderly program in the land sector whose implementation is carried out in an integrated manner and is aimed at all levels of society, especially for the economically weak, as well as resolving completely strategic land disputes. From the above provisions, it is known that the Government's efforts to implement land order can be said to be maximal, we can see from the various legal products issued, the existence of the National Agrarian Program, an institution that specifically handles the land sector (National Land Agency), as well as competent legal institutions to resolve disputes. land
\end{abstract}

Keywords: Registration, Land, Prona.

Abstrak: Pada awalnya Prona dilaksanakan berdasarkan Keputusan Menteri Dalam Negeri No 189 Tahun 1981 Tentang Proyek Operasi Nasional Agraria. Proyek tersebut bertugas untuk memproses pensertifikatan tanah secara masal sebagai perwujudan dari pada program Catur Tertib di bidang Pertanahan yang pelaksanaannya dilakukan secara terpadu dan ditujukan bagi segenap lapisan masyarakat terutama bagi golongan ekonomi lemah, serta menyelesaikan secara tuntas terhadap sengketa-sengketa tanah yang bersifat strategis.Dari ketentuan di atas diketahui bahwa upaya Pemerintah untuk melaksanakan tertib pertanahan bisa dikatakan maksimal, bisa kita lihat dari berbagai produk hukum yang dikeluarkan, adanya Program Nasional Agraria, institusi yang khusus menangani bidang pertanahan (Badan Pertanahan Nasional), serta lembaga hukum yang berkompeten untuk menyelesaikan sengketa pertanahan

Kata Kunci: Pendaftran, Tanah, Prona.

\section{A. Pendahuluan}

Tanah merupakan karunia Tuhan Yang Maha Esa yang menyangkut hidup orang banyak, sehingga tanah mempunyai fungsi yang sangat penting bagi manusia untuk dapat meningkatkan kesejahteraan hidupnya, baik secara lahir maupun batin. Setiap manusia selalu membutuhkan tanah untuk melaksanakan kegiatannya sehari-hari, baik sebagai tempat tinggal maupun sebagai tempat untuk menjalankan usahanya dalam memenuhi kebutuhan hidup dan kehidupanya. Sebutan tanah dalam bahasa kita dapat dipakai dalam berbagai arti, maka dalam menggunakannya perlu diberi batasan, agar diketahui dalam arti apa istilah tersebut digunakan (Boedi Harsono, 1961). Demikian eratnya hubungan manusia dengan tanah, bahkan manusia yang sudah meninggal duniapun membutuhkan tanah sebagai tempat peristirahatanya yang terakhir. Untuk memberikan jaminan kepastian bagi pemegang hak atas tanah di indonesia, maka Undang-Undang Nomor 5 Tahun 1960 (Lembaran Negara Republik Indonesia Tahun 1960 Nomor 104) tanggal 24 September 1960, tentang Peraturan Dasar Pokok- Pokok agrarian (selanjutnya disebut dengan UUPA), telah menggariskan kepada pemerintah agar menyelenggarakan pendaftaran tanah diseluruh wilayah Indonesia.

Setalah berlakunya UUPA, ketentuan pendaftaran tanah termuat dalam pasal 19 ayat (1) UUPA yang berbunyi: "Untuk menjamin kepastian hukum oleh Pemerintah diadakan pendaftaran tanah di seluruh wilayah Republik Indonesia menurut ketentuan-ketentuan yang diatur dengan Peraturan Pemerintah. Diundangkannya UUPA No.5 Tahun 1960 mengakhiri dualisme hukum agraria yang ada sebelumnya berlaku di Indonesia, yakni Hukum Barat yang didasarkan pada Kitab Undang-Undang Hukum Perdata dan Hukum Tanah Adat yang 
didasarkan pada prinsip-prinsip hukum penduduk adat Indonesia, Tujuan Pokok diundangkannya UUPA, yaitu: 1) Meletakkan dasar-dasar bagi penyusunan hukum agraria nasional, yang merupakan alat untuk membawakan kemakmuran, kebahagian dan keadilan bagi Negara dan rakyat; 2) Meletakkan dasar-dasar untuk mengadakan kesatuan dan kesederhanaan dalam hukum pertanahan; dan 3) Meletakkan dasar-dasar untuk memberikan kepastian hukum mengenai hak-hak atas tanah bagi rakyat seluruhnya.

Beranjak dari ketentuan tersebut maka terbitlah Peraturan Pemerintah No.10 Tahun 1961 tentang Pendaftaran Tanah (A.P Parlindungan, 1985). Peraturan Pemerintah tersebut merupakan produk hukum Pemerintah untuk dapat melaksanakan ketentuan Pasal 19 UUPA. Dengan adanya Peraturan tersebut, diharapkan pendaftaran tanah segera dapat dilaksanakan demi terciptanya kepastian hukum dan mengurangi sengketa tanah antara pemilik hak atas tanah. Namun, seiring dengan perkembangan zaman dan muatan-muatan hukum yang terkandung di dalam Peraturan Pemerintah No. 10 Tahun 1961 tidak lagi sesuai dengan kebutuhan hukum masyarakat dalam pendaftaran tanah maka terbitlah Peraturan Pemerintah No. 24 Tahun 1997 tentang Pendaftaran Tanah yang juga menyatakan bahwa Peraturan Pemerintah No. 10 Tahun 1961 tidak berlaku lagi.

Di samping itu, Peraturan Pemerintah No. 24 Tahun 1997 memberikan pengertian tentang Pendaftaran Tanah yang termuat dalam Pasal 1 angka 1, yaitu: Serangkaian kegiatan yang dilakukan oleh Pemerintah secara terus menerus, berkesinambungan dan teratur, meliputi pengumpulan, pengolahan, pembukuan, dan penyajian serta pemeliharaan data fisik dan data yuridis, dalam bentuk peta dan daftar, mengenai bidang-bidang tanah dan satuan-satuan rumah susun, termasuk pemberian surat tanda bukti haknya bagi bidang-bidang tanah yang sudah ada haknya dan hak milik atas satuan rumah susun serta hak-hak tertentu yang membebaninya. 1) Apa langkah pelaksanaan pendaftaran hak atas tanah melalui Program Nasional Agraria (PRONA) di kabupaten Agam? 2) Apa kendala dalam pelaksanaan pendaftaran hak atas tanah melalui Program Nasional Agraria (PRONA) dan upaya penyelesaiannya di kabupaten Agam.

\section{B. Metodologi Penelitian}

Penelitian mengenai Tinjauan Terhadap Pendaftaran Hak Atas Tanah Melalui Program Nasional Agraria (PRONA) di Kabupaten Agam, adalah penelitian hukum yang bersifat Yuridis Empiris, yaitu penelitian yang menitikberatkan pada penelitian terhadap hukum yang diperankan dalam prilaku sosial masyarakat dilakukan dengan terjun langsung kelapangan atau lokasi penelitian untuk memperoleh data yang diperlukan berkaitan dengan obyek penelitian, kemudian data tersebut dijadikan sebagai data primer atau sebagai data pokok.

\section{Hasil dan Pembahasan}

\section{Pelaksanaan Pendaftaran Hak Atas Tanah Melalui Program Nasional Agraria (PRONA) di Kabupaten Agam}

Pelaksanaan Program Nasional Agraria oleh Kantor Pertanahan Kabupaten Agam di bagi dalam beberapa tahapan, yaitu :

1. Penyerahan DIPA (Daftar Isian Pelaksanaan Anggaran). Setelah melalui proses/tahapan usulan, pembahasan, penelaahan di BAPPENAS, DPR-RI, Direktorat Jendral Anggaran, usulan kegiatan dimaksud ditetapkan menjadi DIPA (Daftar Isian Pelaksanaan Anggaran) Induk dan DIPA Petikan, untuk tindak lanjut pelaksanaan DIPA tersebut, terhadap isi DIPA tentang hal-hal sebagai berikut: a) Program Kegiatan dan sub Kegiatan yang memuat anggaran Kegiatan Prona; dan b) Ketersediaan anggaran dan fisik kegiatan (target fisik dan keuangan). Penyusunan POK berdasarkan data yang diperoleh dari penelitian DIPA. Penyusunan POK ini selanjutnya disatukan (diintegrasikan) dengan kegiatan lainya ke dalam POK Satuan kerja.

2. Penetapan Lokasi Prona. Dalam penetapan lokasi kegiatan Prona dilakukan dengan cara sebagai berikut: 1) Kepala Kantor Pertanahan Kabupaten/kota menyusun daftar kecamatan dan desa/kelurahan calon lokassi kegiatan Prona sesuai dengan criteria lokasi

402 Lembaga Penelitian dan Penerbitan Hasil Penelitian Ensiklopedia $\quad$ E-ISSN: 2657-0300

P-ISSN: 2657-0319 
dengan memperhatikan: a) Jumlah golongan ekonomi lemah sampai menegah di Desa/Kelurahan yang bersangkutan; b) Usulan/permintaan kegiatan pensertifikatan tanah dari Pemerintah atau Pemerintah Daerah; dan c) Ketersediaan infrastruktur pendaftaran tanah; 2) Kepala Kantor Pertanahan Kabupaten/kota mengusulkan kecamatan, calon lokasi kegiatan Prona; 3) Kepala Kantor Wilayah BPN Provinsi meneliti dan mengkaji usulan calon kecamatan lokasi kegiatan Prona; 4) Kepala Kantor Wilayah BPN Provinsi menerbitkan Surat Keputusan Kecamatan Lokasi Kegiatan Prona, dan menyampaikan surat keputusan tersebut kepada Kepala Kantor Pertanahan Kabupaten/Kota dengan tembusan kepada Kepala BPN-RI c.q. Sekretaris Utama dan Deputi Bidang Hak Tanah dan Pendaftaran Tanah selaku penanggungjawaban dan Ktua Tim Koordinasi Kegiatan Prona BPN RI; 5) Kepala Kantor Pertanahan Kabupaten/kota menetapkan lokasi Desa/Kelurahan di dalam wilayah kecamatan lokasi Kegiatan Prona sebagaimana dimaksud dalam Surat Keputusan Kepala Kantor Wilayah BPN Provinsi dengan tembusan kepada Kepala BPN-RI c.q. Sekretaris Utama dan Deputi Bidang Hak Tanah dan Pendaftaran Tanah selaku penanggung jawab dan Ketua Tim Koordinasi Kegiatan Prona BPN-RI; 6) Kepala Kantor Wilayah BPN Provinsi dapat merevisi Kecamatan lokasi Kegiatan Prona, atas usulan Kepala Kantor Pertanahan Kabupaten/Kota; dan 7) Kepala Kantor Pertanahan Kabupaten/Kota dapat merevisi desa/kelurahan lokasi Kegiatan Prona sepanjang memenuhi kriteria lokasi. Lokasi kegiatan Prona di Kabupaten Agam adalah adalah Kecamatan Tanjung Raya, Ampek Nagari, Palupuah, Baso, Tilatang Kamang, Tanjung Raya, Candung, Lubuk Basung, Palembayan, Kamang Magek, IV Angkek dan Matua.

3. Kegiatan Penyuluhan. Penyuluhan tentang Prona di Kabupaten Agam di laksanakan di Kecamatan Tanjung Raya, Ampek Nagari, Palupuah, Baso, Tilatang Kamang, Tanjung Raya, Candung, Lubuk Basung, Palembayan, Kamang Magek, IV Angkek dan Matua. Penyuluhan bertujuan untuk memberitahukan kepada pemilik tanah atau kuasanya atau pihak lain yang berkepentingan (Ali Achmad Ghomzah, 2004) bahwa di Nagari tersebut akan diselenggarakan kegiatan Prona. Setelah mengikuti penyuluhan tersebut peserta Prona menjadi memahami dan mengeerti maksud, tujuan, manfaat persyaratan permohonan hak, obyek, subyek kegiatan Prona, hak dan kewajiban peserta Prona, tata kerja dan biaya yang harus ditanggung dalam pendaftaran tanah melalui Prona di Kabupaten Agam.

4. Pengumpulan Data Yuridis. Pengumpulan data yuridis dilakukan oleh Kepala Seksi Hak Atas Tanah dan Pendaftaran Tanah Kantor Pertanahan Kabupaten Agam. Semua bidang Tanah yang didaftarkan melalui Prona di Kabupaten Agam merupakan tanah dengan status pusako tinggi, pusako rendah, dan jual beli. Dalam pembuatan Alas Hak peserta Prona paling bayak 1 Peserta untuk 2 bidang tanah tidak boleh (Heru Sutopo, 2015).

5. Pengumpulan data fisik. a) Kegiatan Pengukuran. Pengukuran dan pemetaan dilakukan oleh Kepala Sub Seksi Pengukuran dan Pemetaan Kantor Pertanahan Kabupaten Agam. Pengukuran dilaksanakan secara bertahap oleh tim yang terdiri dari petugas ukur dari Kantor Pertanahan Kabupaten Agam bersama aparat Nagari setempat, dalam hal ini adalah jorong setempat dan disaksikan oleh pemilik tanah pada waktu yang telah ditentukan. Sebelum dilakukan pengukuran, pemilik tanah atau peserta Prona wajib sudah memasang patok tanda batas yang telah disetujui tetangga bersebelahan sehingga petugas ukur akan lebih mudah dalam melakukan pengukuran. Setelah tanah diukur oleh petugas ukur, maka pemilik tanah yang berbatasan langsung dengan tanah yang diukur wajib membubuhkan tanda tangannya pada Gambar Ukur (GU) yang dibuat oleh petugas ukur. Hasil pengukuran tanah kemudian akan diserahkan ke Kantor Pertanahan Kabupaten Agam untuk dilakukan proses selanjutnya; b) Penerbitan Surat Ukur (SU). Kepala Bidang Pengukuran dan Pemetaan Kantor Pertanahan Kabupaten Agam merupakan pihak yang bertanggung jawab dalam proses penerbitan Surat Ukur (SU) dalam kegiatan Prona. Surat Ukur diterbitkan setelah data yuridis atas tanah beserta hasil pengukuran oleh petugas ukur selesai. 
6. Penggumuman data fisik dan data yuridis, Penggumuman data fisik dan data yuridis dimaksudkan untuk memberikan kesempatan kepada pihak - pihak yang berkepentingan untuk mengajukan keberatan atau sanggahan terhadap data fisik dan data yuridis. Pengumuman dilakukan selama 30 hari. Pengumuman tersebut dipasang di Kantor Pertanahan Kabupaten Agam dan Kantor Wali Nagari. Setelah masa pengumuman berakhir, data fisik dan data yuridis tersebut disahkan oleh Kepala Seksi Hak Atas Tanah dan Pendaftaran Tanah Kantor Pertanahan Kabupaten Agam dan dibuatkan berita acara pengesahan data fisik dan data yuridis.

7. Penerbitan SK Hak/Pengesahan data fisik dan data yuridis. Hak Milik atas tanah yang telah diberikan melalui Surat Keputusan tentang Pengakuan Hak Atas Tanah Adat didaftar dengan cara membukukannya dalam buku tanah yang memuat data yuridis dan data fisik bidang tanah yang bersangkutan serta dicatat pada Surat Ukurnya.

8. Penerbitan Sertifikat. Sertifikat diterbitakan berdasarkan data fisik dan data yuridis yang telah didaftar dalam buku tanah oleh Kantor Pertanahan Kabupaten Agam dan ditanda tangani oleh Kepala Kantor Pertanahan Kabupaten Agam. Sebelum ditandatangi sertifikat diperiksa oleh Kepala Seksi Hak Atas Tanah dan Pendaftaran Tanah Kantor Pertanahan Kabupaten Agam.

9. Penyerahan Sertifikat. Penyerahan sertifikat hak milik atas tanah melalui Prona di Kabupaten Agam dilaksanakan di Kantor Walinagari setempat dengan disaksikan oleh Wali Nagari dan masyarakat dan dibuatkan tanda terima.

Dalam rangka pelaksanaan kegiataan pendaftaran tanah pertama kali legalisasi asset melalui kegiatan Prona, kegiatan yang dibiayai oleh Pemerintah melalui Anggaran Pendapataan dan Belanja Negara (APBN)(DIPA-BPN RI), melupi biaya kegiatan: a) Penyuluhan; b) Pengumpulan data (alas hak/alat bukti); c) Pengukuran bidang tanah; d) Penerbitan SK HAK/Pengesahan Data Fisik dan Data Yuridis; e) Penerbitan Sertifikat; dan f) Survei dan pelaporan. Sedangkan untuk biaya materai dan patok tanda batas, Bea perolehan Hak Atas Tanah dan Bangunan (BPHTB) dan Pajak Penghasilan dari pengalihan Hak Atas Tanah dan Bangunan $(\mathrm{PPh})$ bagi yg terkena ketentuan perpajakan menjdi beban kewajiban peserta program.

\section{Kendala Dalam Pelaksanaan Pendaftaran Hak Atas Tanah Melalui Program Nasional Agraria (PRONA) dan Upaya Penyelesaiannya}

Dalam Proses pendaftaran tanah melaui Prona di Kabupaten Agam ditemui beberapa kendala dalam pelaksanaanya, yakni (Igusnaidy, 2015): a) Keterbatasan pengetahuan masyarakat akan prosedur pendaftaran tanah; b) Kesulitan dalam melengkapi persyaratan yang disyaratkan oleh Kantor Pertanahan Kabupaten Agam, khususnya alas hak dalam dalam pelaksanaan pendaftaran tanah di Kabupaten Agam; c Kurangnya tenaga teknis pengukuran dan administrasi di Kantor Pertanahan Kabupaten Agam sehingga memperlambat proses pendaftaran hak milik adat melalui Prona; dan d) Kurangnya kesadaran masyarakat dalam memasang tanda batas tanah.

Setelah menemui beberapa kendala dalam pendaftaran tanah melalui Prona, Kantor Pertanahan Kabupaten Agam melakukan beberapa upaya, yakni: a) Melakukan penyuluhan secara intensif agar masyarakat bisa lebih memahami prosedur dalam pendaftaran tanah; b) Melakukan penjelasan secara lengkap mengenai pembuatan alas hak agar tidak terjadi kesalahan dalam pengisian persyaratan; c) Menyusun time schedule/jadwal pelaksanaan secara cermat, dengan mempertimbangkan kemampuan dan ketersediaan SDM dibandingkan dengan volume pekerjaan yang ada (meliputi semua tahapan pelaksanaan kegiatan/pekerjaan); dan d) Meningkatkan kesadaran masyarakat akan keguanaan dari tanda batas untuk menghindari sengketa tanah. 


\section{Penutup}

Berdasarkan uraian yang telah penulis kemukakan dalam BAB III dapat ditarik kesimpulan bahwa: Pelaksanaan Pendaftaran Hak Atas Tanah melalui Program Nasional Agraria (PRONA) di Kabupaten Agam dilaksanakan melalui Penyerahan DIPA, Penetapan lokasi, Kegiatan Penyuluhan, Pengumpulan data Yuridis, Pengumpulan data fisik, Pemeriksaan Tanah, Pengumuman data fisik dan yuridis, Penerbitan SK HAK/Pengesahan data fisik dan data yuridis, Penerbitan sertifikat, Penyerahan sertifikat. Dalam hal ini Kantor Pertanahan Kabupaten Agam telah melakukan Pendaftaran tanah sesuai dengan Peraturan Pemerintah Nomor 24 Tahun 1997 Tentang Pendaftaran Tanah dan Peraturan Menteri Agraria dan Tata Ruang/Kepala Badan Pertanahan Nasional Nomor 4 Tahun 2015 Tentang Program Nasional Agraria (PRONA). Kendala dalam Pendaftaran Hak Atas Tanah Melalui Prona adalah masyarakat tidak terlalu memahami mengenai prosedur pendaftaran tanah, sehingga mengakibatkan masyarakat kesulitan dalam pembuatan alas hak untuk didaftarkan.

\section{Daftar Pustaka}

Ali Achmad Ghomzah, Hukum Agraria Pertanahan Indonesia Jilid 2,Jakarta : Prestasi Pustaka.Jakarta

A.P Parlindungan, Pendaftaran dan Konversi Hak-Hak Atas Tanah Menurut UUPA, Bandung Bachtiar Effendi, Pendaftaran Tanah di Indonesia dan Peraturan-peraturan Pelaksanaannya, Bandung

Boedi Harsono.1994. Hukum Agraria Indonesia Sejarah Pembentukan Undang-Undang Pokok Agraria, Isi dan Pelaksanaanya. Jilid 1- Hukum Tanah Nasional, Djambatan, Jakarta

Urip Santoso,Pendaftaran dan Peralihan Hak Atas Tanah, Jakarta, Kencana

Undang-undang Nomor 5 Tahun 1960 Tentang Peraturan Dasar Pokok-pokok Agraria.

Peraturan Pemerintah Nomor 24 Tahun 1997 Tentang Pendaftaran Tanah.

Peraturan Menteri Negara Agraria/Kepala Badan Pertanahan Nasional Nomor 3 Tahun 1997 Tentang Ketentuan Pelaksanaan Peraturan Pemerintah Nomor 24 Tahun 1997 Tentang Pendaftaran Tanah.

Peraturan Menteri Agraria Dan Tata Ruang/Kepala Badan Pertanahan Nasional Nomor 4 Tahun 2015 Tentang Program Nasional Agraria. 